\title{
Erratum zu: Macht Landschaft glücklich
}

\section{Erratum zu: \\ D. Münderlein, Macht Landschaft glücklich, RaumFragen: Stadt - Region - Landschaft , https://doi.org/10.1007/978-3-658-35897-6}

Liebe Leserin, lieber Leser,

vielen Dank für Ihr Interesse an diesem Buch. Leider haben sich trotz sorgfältiger Prüfung Fehler eingeschlichen, die erst nach Drucklegung aufgefallen sind. Auf Wunsch des Autors wurde die Überschrift von Kapitel 5 gekürzt.

Neu: Gesundheit und Erholung in der räumlichen Planung.

Zuvor: Gesundheit und Erholung als Handlungsgegenstand in der räumlichen Planung.

Ferner wurde das elektronischen Zusatzmaterial zu Kapitel 9 aktualisiert.

Die aktualisierte Version des Buches finden Sie unter https://doi.org/10.1007/978-3-658-35897-6

(C) Der/die Autor(en), exklusiv lizenziert durch E1 Springer Fachmedien Wiesbaden GmbH, ein Teil von Springer Nature 2021 D. Münderlein, Macht Landschaft glücklich, RaumFragen: Stadt - Region Landschaft, https://doi.org/10.1007/978-3-658-35897-6_11 